\title{
A Metamaterial inspired elliptical slotted antenna for WLAN and uplink /downlink X-bands Rejection
}

\author{
Mourad Elhabchi ${ }^{*}$, Mohamed Nabil Srifi ${ }^{2}$, Raja Touahni ${ }^{3}$ \\ \{mouradelhabchi@hotmail.fr,srifimn@ieee.org,touahni-raja@univ-ibntofail.ac.ma\} \\ ${ }^{1 *}, 3$ LASTID Laboratory, Department of physics, Faculty of Sciences, Ibn Tofail University \\ ,kenitra,morocco, mouradelhabchi@hotmail.fr and touahni-raja@univ-ibntofail.ac.ma \\ ${ }^{2}$ Electronics and Telecommunication Systems Research Group, National School of Applied Science \\ (ENSA), Ibn Tofail University, kenitra,morocco, srifimn@ieee.org
}

\begin{abstract}
In this communication, we propose a metamaterial inspired conventional elliptical slotted coplanar waveguide (CPW) UWB antenna for dual band-notched features. Initially, the operating frequency range is from $4 \mathrm{GHz}$ to $12 \mathrm{GHz}$. To filter the undesired WLAN $(5-6 \mathrm{GHz})$ and uplink and downlink of X-band satellite communication systems ( 7.25 to $8.39 \mathrm{GHz})$ frequency bands, we are loaded respectively a symmetrical dual split ring resonator metamaterials SRR as a defected ground plane slots (DGS) and a single split ring resonator metamaterial (SRR) as a strip on the top edge of the radiating slotted elliptical antenna.The performance of the antenna is simulated both by CST Microwave Studio and Ansoft HFSS .To analyze the effects of the SRR slot and strips , the surface current distribution is used. The antenna gain versus frequency is acceptable except the notched band regions, its value is reduced from its normal to be a negative value in $(5-6 \mathrm{GHz})$ and $(7.25$ to $8.39 \mathrm{GHz})$ suppressed bands.
\end{abstract}

Keywords: metamaterial; UWB antenna; split ring resonator; defected ground plane; band-notched.WLAN; X-band.

\section{Introduction}

Since February 2002 when the Federal Communications Commission (FCC) allocated the frequency range from $3.1 \mathrm{GHz}$ to $10.6 \mathrm{GHz}$ to be a free band with a good effective radiated power spectral density of $-41.3 \mathrm{dBm} / \mathrm{MHz}[1]$, the UWB systems become very attractive. However, there are several other excite technologies for a long time that can interfere with the UWB band systems, such as Wireless Local Area Network (WLAN) in the 5.15-5.825GHz band and 7.25-7.75 GHz band for downlink of X-band satellite communication systems.

Several published papers focus their research to filter the unwanted frequency spectrums.A.Yadav et al uses three rectangular slots loaded CPW - feed ultrawideband (UWB) to create dual band-notched [2] .B. Li et al studied a switched coplanar waveguide (CPW) dual stop-band antenna using a rectangular ring slot, two inverted S-shaped slots and four switches with a T-shaped radiating patch[3] .A microstrip UWB monopole structures with dual band-rejected characteristics based on single tri-arm resonator[4], parasitic slots[5], loading Open-Looped Resonator element in an UWB design [6] ,the $\pi$-shaped slit [7] the slotted elliptical UWB antenna with half circular ring radiator elements [8],T-shaped stubs and capacitive-load strips [9].Other resonator forms, such as the elliptic single complementary 
split-ring resonators and rectangular split-ring resonators are etched in microstrip-fed UWB antenna [10],[11], on the hook-shaped defected ground structure (DGS) and semi-octagonshaped resonant ring of the antenna [12].

In this letter, a conventional slotted elliptical UWB antenna has been modified to obtain a dual notched characteristic [14]. The split ring resonator(SRR) metamaterial is used as a defected ground plane(DGS) and a loaded strip to affect in the antenna behaviors and to filter the unwanted bands for WLAN and X-band satellite communication systems respectively. However, in order to realize the eliminated band in the WLAN region, a dual symmetrical DSG SRR are etched in the ground plane. The X-band elimination is achieved by loading a single SRR in the top edge of the radiating slotted element. The filtered bands can be controlled easily by tuning the length and widths of the matamaterial slots. The performances of the proposed design have been investigated, and the simulated results both in CST Microwave and Ansoft HFSS are presented.

\section{Antenna design}

The details and configurations of the proposed dual band notched elliptical slotted shaped are illustrated in fig. 1. The antenna is printed on a $20 \times 24 \mathrm{~mm}^{2}$ layer of dielectric substrate FR4 with a permittivity of $\varepsilon_{\mathrm{r}}=4.3$, loss tangent of $\tan \delta=0.025$ and height of $\mathrm{h}=$ $1.6 \mathrm{~mm}$.To achieve $50 \Omega$ impedance adaptation, the width of the feed line is fixed at $\mathrm{wf}=2.6 \mathrm{~mm}$. The dimensions of the proposed elliptical multiple band antenna are: $\mathrm{Ws}=20 \mathrm{~mm}$, $\mathrm{Ls}=42 \mathrm{~mm}, 1 \mathrm{f}=7.8 \mathrm{~mm}, \mathrm{wg}=8.4 \mathrm{~mm}, \mathrm{Lg}=7 \mathrm{~mm}, \mathrm{Wt}=1 \mathrm{~mm}, \mathrm{Lt}=17 \mathrm{~mm}, \mathrm{Wp} \mathrm{p}_{1}=2.5 \mathrm{~mm}, \mathrm{Lp}=6 \mathrm{~mm}$, $\mathrm{Ea}=3 \mathrm{~mm}, \mathrm{~Eb}=5 \mathrm{~mm}, \mathrm{Wr}_{1}=5.5 \mathrm{~m}, \mathrm{Wr}_{2}=8 \mathrm{~mm}, \mathrm{Lr}_{1}=5 \mathrm{~mm}, \mathrm{Lr}_{2}=7.5 \mathrm{~mm}, \mathrm{Gr}_{1}=1 \mathrm{~mm}, \mathrm{Gr}_{2}=1 \mathrm{~mm}$.

In order to excite the desired bands elimination in the frequency ranges of (5-6) $\mathrm{GHz}$ for WLAN rejection, a dual symmetrical split ring resonators (DGS) SRR metamaterial are etched in the CPW ground plane as shown in (fig. 2.Ant II). The unwanted bandstop for uplink and downlink of $\mathrm{X}$-band satellite communication systems $(7.25$ to $8.39 \mathrm{GHz})$ is achieved when the researchers have been loaded the top edge of the radiating element with a single split ring resonators SRR metamaterial as a strip (fig. 2.Ant III). defining dimensions and position of introduced SRR metamaterial are one of the essential elements on band notched antenna design [13] Usually, the length of the slot is made approximately equal to half the guided wavelength at the notch frequency of the band[13].

$$
\begin{aligned}
& \mathrm{L}_{\text {Total-wlan }}=\frac{\lambda_{\mathrm{g}}}{2}=\frac{\mathrm{c}}{2 \mathrm{f}_{\text {notch-wlan }} \sqrt{\frac{\varepsilon_{\mathrm{r}+1}}{2}}} \\
& \mathrm{~L}_{\text {Total-X-band }}=\frac{\lambda_{\mathrm{g}}}{2}=\frac{\mathrm{c}}{2 \mathrm{f}_{\text {notch-X-band }} \sqrt{\frac{\varepsilon_{\mathrm{r}+1}}{2}}}
\end{aligned}
$$

Where $\mathrm{L}_{\text {total wLAN }}$ is the total length of the DGS SRR metamaterial slot and $\mathrm{L}_{\text {total }} \mathrm{x}$ band is the total length of the loaded SRR metamaterial strip . by a way of CST and HFSS simulations we can determine and find the exact filter band.

The $S_{11}$ parameters for different antenna designs are illuminated in the figure. 3 . Including those of the initial reference antenna(fig.3.Ant I) [14]. As seen in figure.3, a dual symmetrical (DGS) SRR slotted on in the CPW ground plane leads to exhibits a single rejected band covering the entire WLAN band(fig. 3.Ant II), the rejected X-band is achieved when loading a single SRR on top edge of the radiating patch(fig. 3.Ant III). 


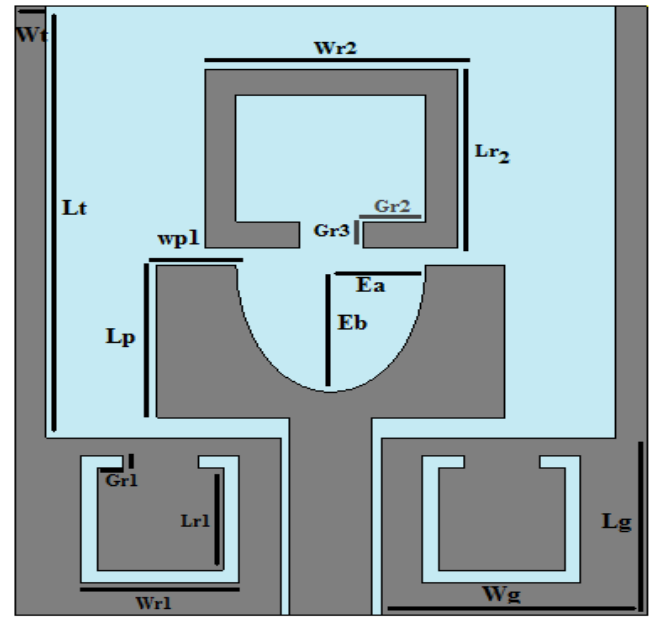

Fig. 1. The Geometry of proposed dual band notched metamaterial antenna.

Fig. 2. shows the evolution stages step by step of the proposed design.
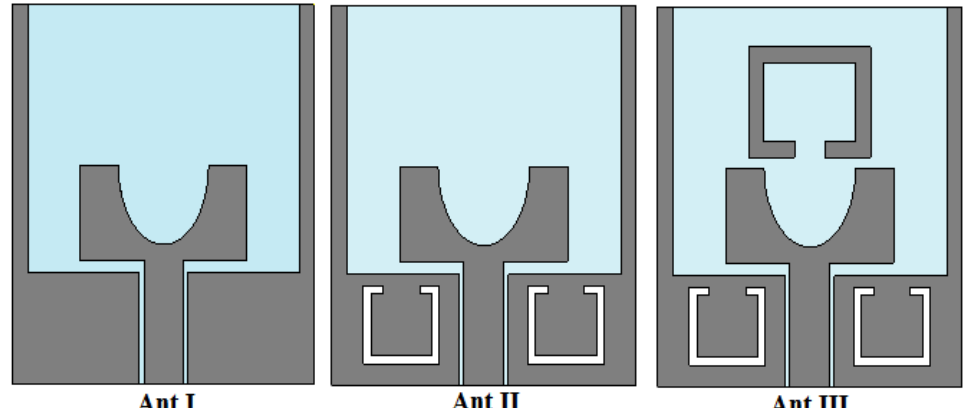

Fig. 2. The structures of the prototype and proposed antennas. Ant I: reference antenna,. Ant II: antenna with DGS SRR metamaterial. Ant III: antenna with both (DGS) SRR and loaded SRR stip.

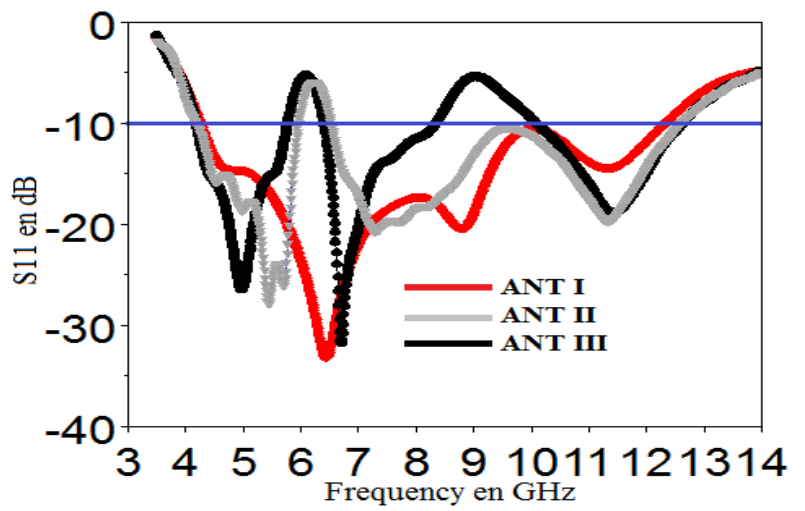

Fig. 3. The Simulated return loss for Ant I, Ant II and Ant III. 


\section{Parametric Study and Observation}

\subsection{The WLAN stop band}

A parametric study is carried out to determine the influence of the essential parameters on the impedance adaptation as shown in fig. 1. Witch depicts the configuration of the proposed antenna. Figure 4 illustrates the effects of DGS SRR slot width $\mathrm{Wr}_{1}$ dimensions. As shown, the rejected signal is shifted from 6.7 to $5.7 \mathrm{GHz}$ when $\mathrm{Wr}_{1}$ decrease from 6 to $4.5 \mathrm{~mm}$.

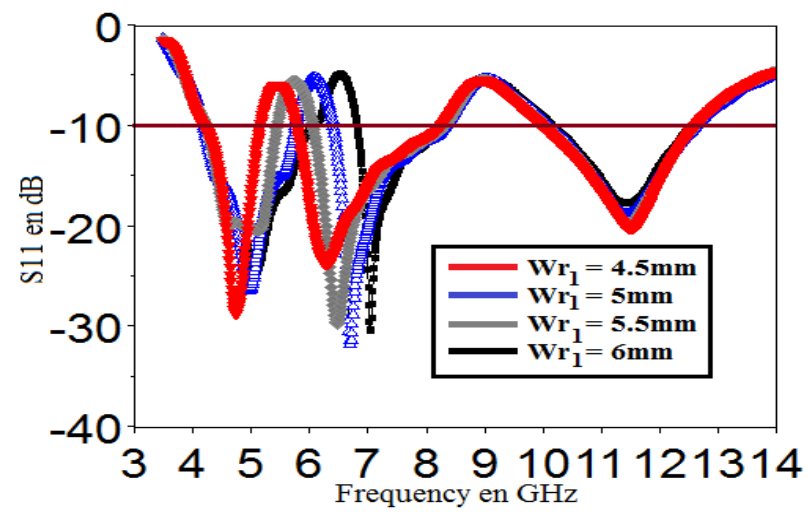

Fig. 4. Simulated reflection coefficient for different $\mathrm{Wr}_{1}$

Moreover, the $\mathrm{S}_{11}$ traces increases from $-7 \mathrm{dBi}$ to $-3 \mathrm{dBi}$ and shifted to the higher frequency when the length of the DGS SRR $\operatorname{Lr}_{1}$ value varies from 5.5 to $4 \mathrm{~mm}$ (fig. 5.)..

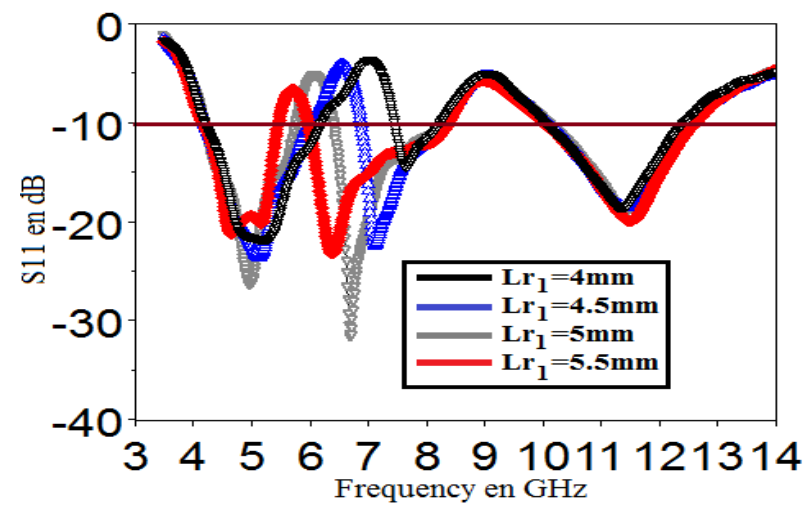

Fig. 5. Simulated reflection coefficient for different $\mathrm{Lr}_{1}$ 
Figure. 6 shows the $S_{11}$ parameters for different values of the DGS SRR slot gap $\mathrm{Gr}_{1}$, It can be observed that the return loss $S_{11}$ at the eliminated bands are significantly dependent on the $\mathrm{Gr}_{1}$ values.

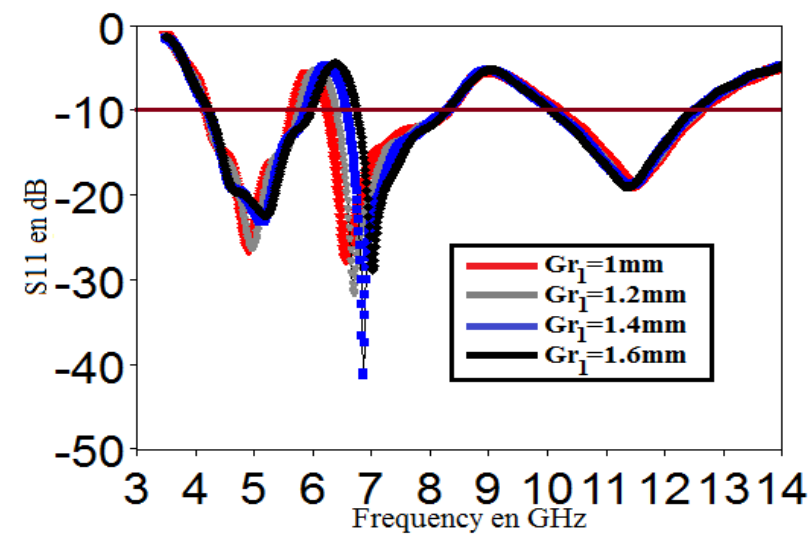

Fig. 6. Simulated reflection coefficient for different $\mathrm{Gr}_{1}$

\subsection{The uplink and downlink eliminated X-band}

Figure 7 illuminates the influence of loaded SRR strip width $\mathrm{Wr}_{2}$ values. As observed, the stopped signal to the lower frequency with desired worse impedance when $\mathrm{Wr}_{2}$ increase from 6 to $9 \mathrm{~mm}$.

Thereafter, the effect of loaded SRR stub length is shown in figure 8, It can be concluded that the return loss $S_{11}$ at the rejected bands varies when $\operatorname{Lr}_{2}$ values increase from 6.5 to $8 \mathrm{~mm}$ with a little effects on the low frequency due to the couplage between SRR metamaterial elements .

Figure. 9 illustrates the $S_{11}$ parameters for different values of the SRR strip gap $\mathrm{Gr}_{3}$, It can be observed that the $S_{11}$ at the unwanted bands are significantly affected when the $\mathrm{Gr}_{3}$ value changes.

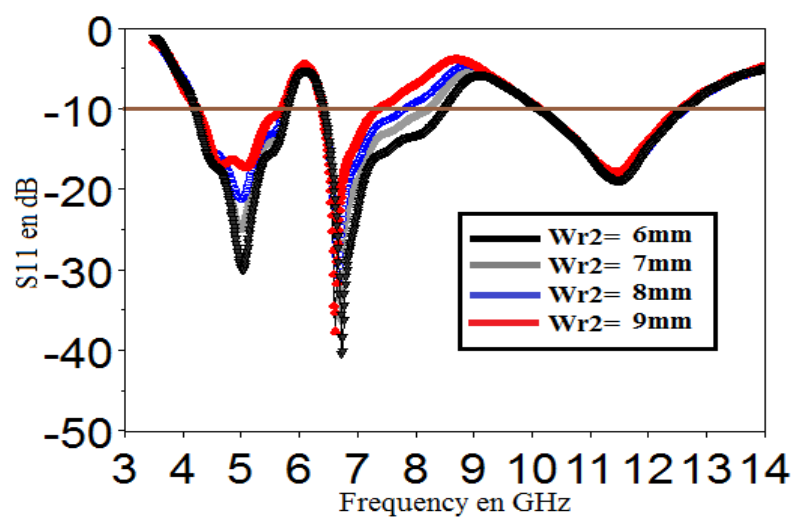

Fig. 7. Simulated $\mathrm{S}_{11}$ for different $\mathrm{Wr}_{2}$ 


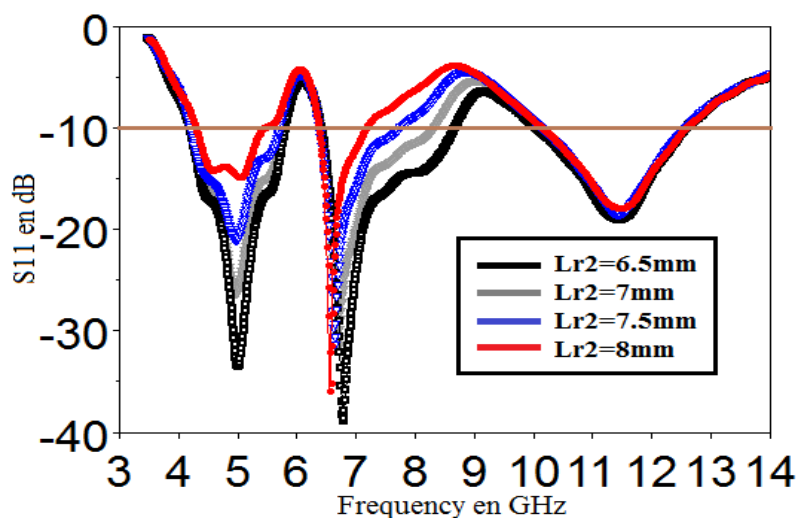

Fig. 8. Simulated $\mathrm{S}_{11}$ for different $\mathrm{Lr}_{2}$

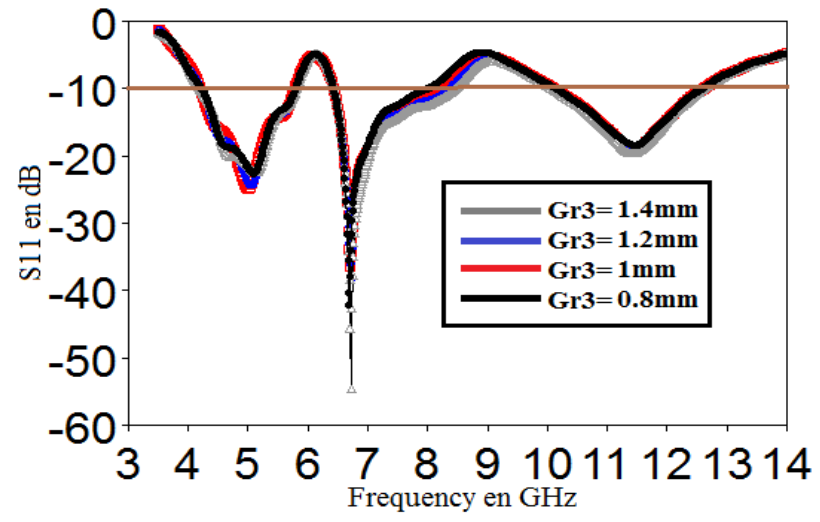

Fig. 9. Simulated $\mathrm{S}_{11}$ for different $\mathrm{Gr}_{3}$

\section{Current Distributions and Radiation Pattern Results}

To understand the generation of the filtred bands Figure.10 depicts the current distributions density at $5.5 \mathrm{GHz}$ and $8 \mathrm{GHz}$, The current is significantly important in DGS SRR slot (fig.10.a) with very current concentration in the rest part of the antenna which denotes that the loaded SRR slot metamaterials reject the WLAN band,

Figure 10 (b) illustrate the surface currents at $8 \mathrm{GHz}$, as observed in this figure the currents is important and highly distributed around the SRR loaded metamaterial strip comparing to the other part of the antenna. Therefore, the antenna relexion coefficient changed at these frequencies due to the insertion of SRR metamaterial as a slots and strip witch introduces additional paths to the surface currents at rejected signals.

Figure 11 illuminates the simulated radiation patterns both in E-plane $\left(\mathrm{phi}=0^{\circ}\right)$ and $\mathrm{H}$-plane (phi $=90^{\circ}$ ) of the proposed design using CST software at sample selected frequencies of 4.5 and $10 \mathrm{GHz}$. It is observed that the proposed UWB antenna with dual stop band provide omnidirectional radiation patterns E-plane and stable bi-directional radiation patterns in $\mathrm{H}$ - 
plane (have two main principle lobes) with a shift inaccuracy in the high frequency $(10 \mathrm{GHz})$ .which is obvious represents the same characteristics to those of dipole antennas.

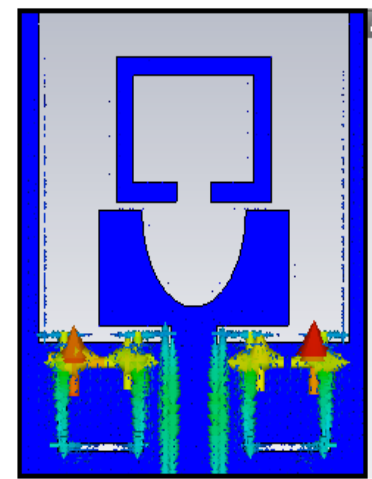

(a)

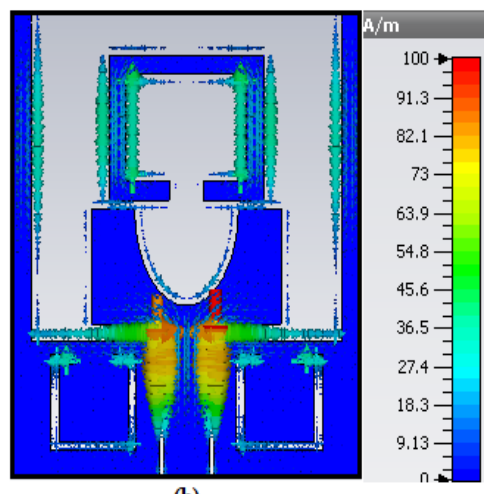

(b)

Figure 10. Current distributions at (a) $5.5 \mathrm{GHz}$, (b) $8 \mathrm{GHz}$

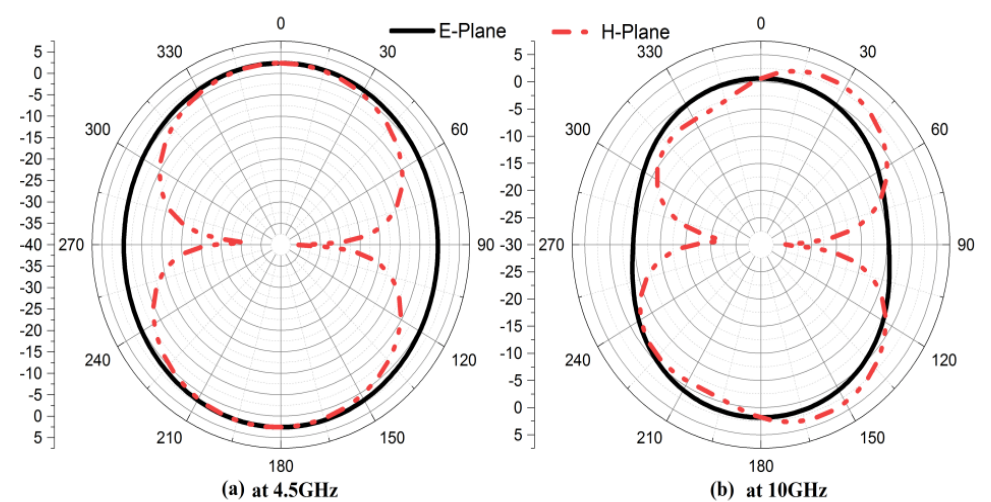

Fig. 11. Simulated radiation pattern at each selected frequencies in E-plane (solid line) and H-plane (dash dot line).

The simulated peak gain of the initial UWB structure and the proposed filtered signal antenna versus the UWB frequency range (3-14 GHz) are illustrated in figure.12. The obtained results have illuminated that substantial reductions in peak gain can be observed at the stopband frequencies.

To validate to simulated results achieved with the CST software. We designed and optimized against the proposed dual band notched antenna as HFSS to compare the results of our concept. Figure. 13 present the return loss $\mathrm{S}_{11}$ obtained by both CST and HFSS softwares. 


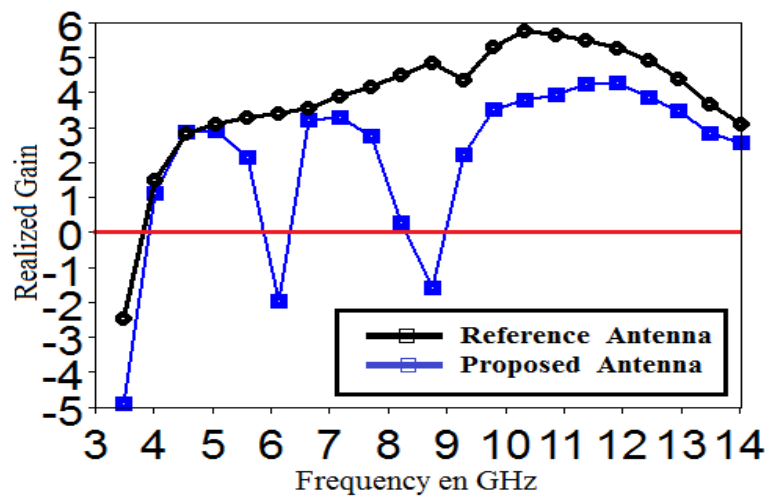

Figure. 12. The simulated gain values of the reference and modified UWB antenna.

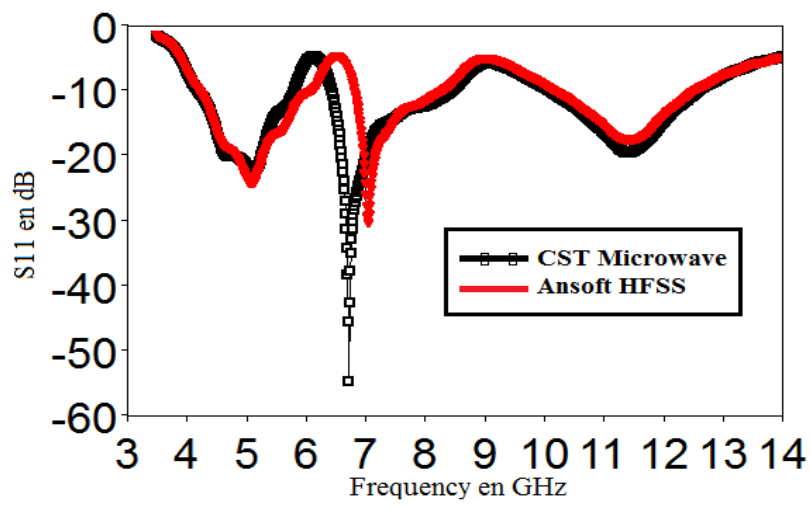

Figure 13. Comparison between the $\mathrm{S}_{11}$ versus frequency.

\section{Conclusion}

In this article, a UWB slotted elliptical with dual band notched characteristics have been presented and investigated, a dual split ring resonator metamaterials SRR as a defected ground plane slots(DGS) and a single split ring resonator metamaterials (SRR) as a stub on the top edge of the radiating antenna to avoid interference with the unwanted WLAN (5$6 \mathrm{GHz})$ and uplink and downlink of X-band satellite communication systems (7.25 to 8.39 $\mathrm{GHz}$ ) frequency bands. The bandwidths of these bands stop metamaterials can be adjusted and controlled by the dimensions of the SRR strip and slots. The prototype antenna has been simulated with CST and HFSS to validate against the obtained results.

\section{References}

[1] Federal Communications Commission Revision of Part 15 of the Commission's Rules Regarding Ultra-Wideband Transmission System from 3.1 to $10.6 \mathrm{GHz}$ Federal Communications Commission. Washington, DC, ET-Docket, pp. 98-153, FCC.(2002). 
[2] Yadav, A. and Sethi, D. and Khanna, R.K.: Slot Loaded UWB Antenna: Dual Band Notched Characteristics.Vol. 70(3), pp. 331-335. AEU-International Journal of Electronics and Communications (2016).

[3] Li, B. and Hong, j. and Wang, B.:Switched Band-Notched UWB/Dual-Band WLAN Slot Antenna With Inverted S-Shaped Slots.Vol. 11, pp. 572-575. IEEE Antennas and Wireless Propagation Letters (2012).

[4] Azim, R. and Islam, M.T. and Mobashsher, A.T.: Dual Band-Notch UWB Antenna With Single Tri-Arm Resonator. Vol. 13 , pp. 670-673. IEEE Antenna. Wireless Propag. Lett, (2014).

[5] Elhabchi, M. Srifi, M.N. and Touahni, R.: A Novel Dual Band Hexagonal Antenna for Bluetooth and Uwb Applications With Single Band Notched. Vol. 7, no. 5,pp. 63-67. Advanced Electromagnetics.( 2018).

[6] Chu, Q. X. and Yang, Y. Y. : A compact ultrawideband antenna with 3.5/5.5 GHz dual bandnotched characteristic. Vol. 56, no. 12, pp. 3637-3644, IEEE Trans. Antennas Propag. (2008).

[7] Zhao, Y. L. and Jiao, Y. C. and Zhao, G. and Zhang, L. Song, Y. and Wong, Z. B.:Compact planar monopole UWB antenna with band- notched characteristic. Vol. 50, pp. 2656-2658. Microwave Opt. Technol. Lett.(2008).

[8] Elboushi, A. Ahmed, O.M. and Sebak, A.R.:Study of elliptical slot UWB antennas with a 5.0$6.0 \mathrm{GHz}$ band-notch capability. Vol. 16, pp.207-222. Progress In Electromagnetics Research C.(2010).

[9] Lin, C. C. Jin, P. and Ziolkowski, R. W. :Single, dual and tri-bandnotched ultrawideband (UWB) antennas using capacitively loaded loop (CLL) resonators. Vol. 60, no. 1, pp. 102-109.IEEE Trans. Antennas Propag.( 2012).

[10] Cho, Y-J. Kim, K.-H. Choi, D-H. Lee, S-S. and Park, S-O.: A miniature UWB planar monopole antenna with 5-GHz band-rejection filter and the time-domain characteristics. Vol. 54, no. 5, pp. 1453-1460. IEEE Trans. Antennas Propag. (2006).

[11] Sarkar, D. Srivastava, K.V. and Saurav, k.: A Compact Microstrip-Fed Triple Band-Notched UWB Monopole Antenna. Vol. 13, pp. 396-399. IEEE Antenna. Wireless Propag. Lett,(2014).

[12] Li, W-T. Shi, X-W. and Hei Y- Q.:Novel Planar UWB Monopole Antenna With Triple BandNotched Characteristics. Vol. 8, pp .1094 - 1098. IEEE Antenna. Wireless Propag. Lett.(2009).

[13] Gao, G. P. Mei, Z. L. and Li, B. N.:Novel Circular Slot UWB Antenna With Dual BandNotched characteristic. Vol. 15, pp .49-63. Progress In Electromagnetics Research C. (2010).

[14] Xu, K. Zhu, Z. Li, H. Huangfu, J. Li, C. and Ran, L. : A Printed Single-Layer UWB Monopole Antenna With Extended Ground Plane Stubs. Vol .12. IEEE Antenna. Wireless Propag. Lett (2013). 